\title{
Near-fatal haemorrhage from pulmonary arteriovenous malformation in HHT with increased cardiac output
}

\section{To the Editor:}

We read with interest the report by MONTANI et al. [1] of fatal rupture of pulmonary arteriovenous malformation (AVM) in a patient with hereditary haemorrhagic telangiectasis (HHT) and severe pulmonary arterial hypertension (PAH) confirmed by right heart catheterisation. The authors hypothesised that bleeding from pulmonary AVM may have been facilitated by increased mean pulmonary artery pressure $(P$ pa). Here, we report a patient with near-fatal haemorrhage from pulmonary AVM, probably facilitated by increased cardiac output, but without severe PAH.

A 35-yr-old female nonsmoker, with a history of obesity and fenfluramide use $10 \mathrm{yrs}$ previously for 2 months, was admitted for exertional dyspnoea during pregnancy. Arterial blood gases showed arterial oxygen tension $\left(\mathrm{Pa}_{1} \mathrm{O}_{2}\right)$ of $8.2 \mathrm{kPa}$, and arterial carbon dioxide tension of $3.5 \mathrm{kPa}$, with markedly increased alveolar-arterial oxygen tension difference on $100 \%$ oxygen $(74 \mathrm{kPa}$, normally $<18.6 \mathrm{kPa})$. Chest radiograph revealed numerous pulmonary AVMs. Transthoracic contrast echocardiography showed estimated systolic $P$ pa of $47 \mathrm{mmHg}$ with moderate dilatation of the right heart cavities, and extracardiac right-to-left shunting. She had recurrent epistaxis since childhood, numerous characteristic telangiectasiae, and possible familial HHT in her paternal grandmother. HHT was diagnosed according to the Curaçao criteria [2]. One deletion was found in exon 9 of the ENG gene, and analysis of the ACVRL1 gene was normal. Long-term oxygen therapy was initiated. Emergency caesarean delivery was performed at 25 weeks of gestation because of a fetal growth defect.

2 months after delivery, dyspnoea was New York Heart Association functional class III, with cyanosis and hepatic murmur on auscultation. Pulmonary function tests were normal. Room air $\mathrm{Pa}_{1} \mathrm{O}_{2}$ was $6.7 \mathrm{kPa}$. The 6-min walk distance was $305 \mathrm{~m}$ with a reduction in arterial oxygen saturation from $89 \%$ to $78 \%$ on $6 \mathrm{~L} \cdot \mathrm{min}^{-1}$ nasal oxygen. Computed tomography (CT) of the chest and abdomen demonstrated fifteen bilateral pulmonary AVMs, and numerous liver AVMs with increased diameter of the hepatic artery $(10 \mathrm{~mm})$. Right heart cavities were no longer dilated at echocardiography; estimated cardiac output was $10.6 \mathrm{~L} \cdot \mathrm{min}^{-1}$. At right heart catheterisation, $P$ pa (systolic/diastolic/mean) was 32/ $18 / 23 \mathrm{mmHg}$, pulmonary artery wedge pressure was $18 \mathrm{mmHg}$, right atrial pressure was $13 \mathrm{mmHg}$, cardiac output was 11.4 $\mathrm{L} \cdot \mathrm{min}^{-1}$, cardiac index was $5.6 \mathrm{~L} \cdot \mathrm{min}^{-1} \cdot \mathrm{m}^{-2}$, pulmonary vascular resistance was $35 \mathrm{dyn} \cdot \mathrm{s} \cdot \mathrm{cm}^{-5}$, and left-to-right shunting was estimated to be $4.35 \mathrm{~L} \cdot \mathrm{min}^{-1}$ with pulmonary/systemic blood flow ratio of 1.78. Transcatheter vaso-occlusion of pulmonary AVMs was postponed because of moderately increased $P$ pa. The balloon occlusion test was not feasible due to the number of high-flow pulmonary AVMs. Liver transplantation was considered as future therapeutic option. Treatment with propranolol $40 \mathrm{mg}$ b.i.d. was initiated to decrease cardiac output, which was later estimated at $6.5 \mathrm{~L} \cdot \mathrm{min}^{-1}$ on echocardiography under treatment. Clinical and haemodynamic parameters were stable for 15 months.

The patient was readmitted in emergency for massive haemoptysis ( $\sim 500 \mathrm{~mL}$ per day for 3 days), with dyspnoea at rest and tachypnoea. Her haemoglobin level had dropped from 170 to $100 \mathrm{~g} \cdot \mathrm{L}^{-1}$. CT scan of the chest (fig. 1) showed new ground-glass opacities in the left upper lobe and adjacent to one pulmonary AVM. Fibreoptic bronchoscopy showed abundant fresh blood in the upper left bronchus. Attempts at percutaneous transcatheter vaso-occlusion of the bleeding pulmonary AVM failed, because of a very short feeding artery; mean Ppa during the procedure was $28 \mathrm{mmHg}$ in the left pulmonary artery and $24 \mathrm{mmHg}$ in the right pulmonary artery. Due to persistent haemoptysis, the patient underwent open thoracic surgery, with sublobar resection of left apical posterior segments which comprised a complex pulmonary AVM (three afferent and two efferent large vessels). Percutaneous vaso-occlusion of large bilateral pulmonary AVM of the lung bases was performed in the following weeks, with mean $P$ pa of $27 \mathrm{mmHg}$ (right side) and $32 \mathrm{mmHg}$ (left side) measured during the procedure. 2 yrs later, haemoptysis had not recurred. Echocardiography showed no evidence of $\mathrm{PAH}$, and estimated cardiac output was $7.5 \mathrm{~L} \cdot \mathrm{min}^{-1} \cdot \mathrm{Pa}_{1} \mathrm{O}_{2}$ was $7.6 \mathrm{kPa}$ on $6 \mathrm{~L} \cdot \mathrm{min}^{-1}$ nasal oxygen.

Whereas complications of pulmonary AVMs are mostly cerebral ischaemic strokes and systemic severe infections, including cerebral abscesses [3], rupture of pulmonary AVMs may occur rarely [3] and lead to massive haemoptysis or haemothorax, which may be lethal [1,4]. Although high-flow pulmonary AVMs contribute to low pulmonary vascular resistance and may, therefore, protect from pulmonary hypertension, they may coexist with pulmonary hypertension in a small proportion of HHT patients, with significant challenge for clinical management.

Pulmonary hypertension in HHT may result from increased cardiac output and hyperdynamic state or, rarely, it may be isolated and similar to idiopathic PAH [5]. When present, severe $\mathrm{PAH}$ is usually considered a contraindication for vaso-occlusion of pulmonary AVMs, because of potential worsening of the pulmonary hypertension [6] and a possible increased risk associated with the procedure [4]. However, vaso-occlusion of pulmonary AVMs does not consistently increase the mean $P$ pa in HHT patients without severe pulmonary hypertension [7], although the Ppa may increase in selected individuals. 

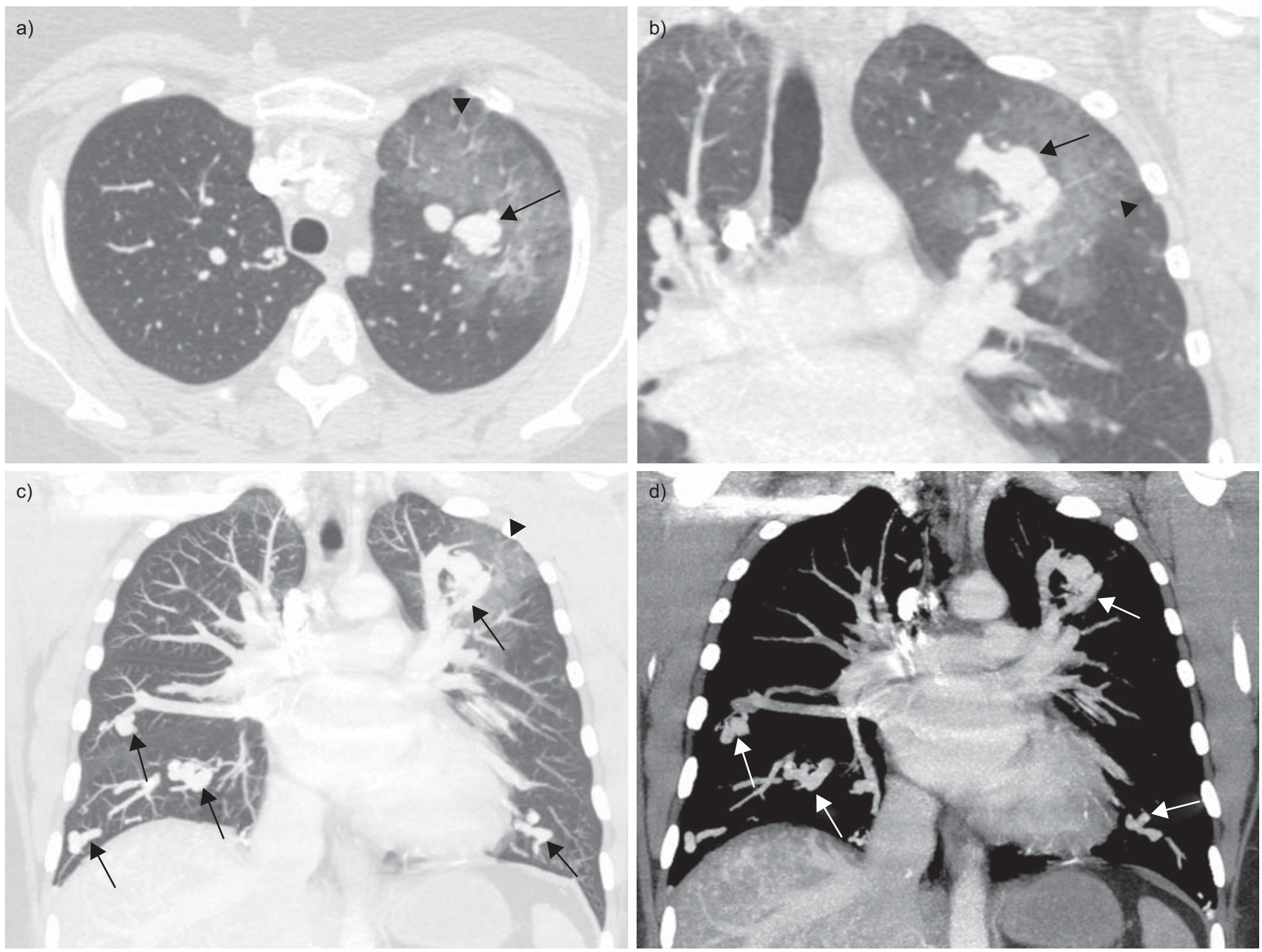

FIGURE 1. Computed tomography of the chest at the time of severe haemoptysis demonstrating numerous bilateral pulmonary arteriovenous malformations (arrows), with ground-glass opacities in the left upper lobe, indicating haemorrhage (arrowheads)

Increased cardiac output and heart failure resulting from liver AVMs is more common than PAH in HHT. Right heart catheterisation demonstrates elevated $\mathrm{Ppa}$, with increased cardiac index, normal or decreased pulmonary vascular resistance, and possibly increased pulmonary capillary wedge pressure. Vaso-occlusion of pulmonary AVMs in this context may unmask moderate pulmonary hypertension [6] and, conversely, may contribute to a decrease in cardiac output [7]. Management of HHT patients with high-output cardiac failure is difficult; correction of anaemia, liver transplantation [8], banding of the hepatic artery [9], bevacizumab [10] and, possibly, arterial embolisation of liver AVMs (but with a significant risk of complications) may be considered. No recommendation is available regarding the management of pulmonary AVMs in patients with increased cardiac output.

In our patient, we interpret that increased cardiac output due to both liver AVMs and to pregnancy may have contributed to enlargement and increased risk of rupture of the pulmonary AVMs. The mean Ppa was only mildly elevated and probably did not cause rupture of the pulmonary AVM. However, as in the case reported by MONTANI et al. [1], vaso-occlusion of the pulmonary AVMs would probably have prevented the haemorrhage, although no evidence is available.

Our observation supports the notion that the theoretical risk of increasing the $P$ pa by vaso-occlusion of the pulmonary AVMs should be carefully balanced with the significant risk of complications, including massive haemorrhage [11]. It further suggests that an increased risk of bleeding of pulmonary AVMs may be associated not only with elevated Ppa but also with increased cardiac output, often due to liver AVMs.

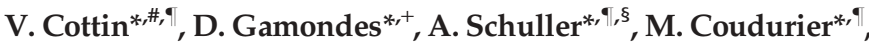
S. Dupuis-Girod ${ }^{\S, f}$, F. Tronc ${ }^{*, * *}$ J-F. Cordier, ${ }^{*, * \text {, }}$

*Hôpital Louis Pradel, Hospices civils de Lyon, ${ }^{+}$Service de radiologie, Hôpital Louis Pradel, Hospices civils de Lyon, **Service de chirurgie thoracique et cardiovasculaire, Hôpital Louis Pradel, Hospices civils de Lyon, ${ }^{\dagger}$ Service de génétique, 
Hôpital de l'Hôtel-Dieu, Hospices civils de Lyon, ${ }^{\S}$ Université Lyon I, Université de Lyon, " INRA, UMR754, Université Lyon I, Université de Lyon, and "Service de pneumologie, Centre de référence des maladies pulmonaires rares, Lyon, France.

Correspondence: V. Cottin, Hôpital Louis Pradel, 69677 Lyon (Bron) Cedex, France. E-mail: vincent.cottin@chu-lyon.fr

Support Statement: This study was supported by Hospices Civils de Lyon, Lyon, France.

Statement of Interest: None declared.

Provenance: Submitted article, peer reviewed.

\section{REFERENCES}

1 Montani D, Price LC, Girerd B, et al. Fatal rupture of pulmonary arteriovenous malformation in hereditary haemorrhagic telangiectasis and severe PAH. Eur Respir Rev 2009; 18: 42-46.

2 Shovlin CL, Guttmacher AE, Buscarini E, et al. Diagnostic criteria for hereditary hemorrhagic telangiectasia (Rendu-Osler-Weber syndrome). Am J Med Genet 2000; 91: 66-67.

3 Cottin V, Chinet T, Lavole A, et al. Pulmonary arteriovenous malformations in hereditary hemorrhagic telangiectasia: a series of 126 patients. Medicine (Baltimore) 2007; 86: 1-17.
4 Pelage JP, Lagrange C, Chinet T, et al. Embolization of localized pulmonary arteriovenous malformations in adults. J Radiol 2007; 88: 367-376.

5 Cottin V, Dupuis-Girod S, Lesca G, et al. Pulmonary vascular manifestations of hereditary hemorrhagic telangiectasia (RenduOsler disease). Respiration 2007; 74: 361-378.

6 Haitjema T, ten Berg JM, Overtoom TTC, et al. Unusual complications after embolization of a pulmonary arteriovenous malformation. Chest 1996; 109: 1401-1404.

7 Shovlin CL, Tighe HC, Davies RJ, et al. Embolisation of pulmonary arteriovenous malformations: no consistent effect on pulmonary artery pressure. Eur Respir J 2008; 32: 162-169.

8 Boillot O, Bianco F, Viale JP, et al. Liver transplantation resolves the hyperdynamic circulation in hereditary hemorrhagic telangiectasia with hepatic involvement. Gastroenterology 1999; 116: 187-192.

9 Koscielny A, Willinek WA, Hirner A, et al. Treatment of high output cardiac failure by flow-adapted hepatic artery banding (FHAB) in patients with hereditary hemorrhagic telangiectasia. $J$ Gastrointest Surg 2008; 12: 872-876.

10 Mitchell A, Adams LA, MacQuillan G, et al. Bevacizumab reverses need for liver transplantation in hereditary hemorrhagic telangiectasia. Liver Transpl 2008; 14: 210-213.

11 Shovlin C, Gibbs JSR, Jackson JE. Management of pulmonary arteriovenous malformations in pulmonary hypertensive patients: a pressure to embolise? Eur Respir Rev 2009; 18: 4-6.

DOI: $10.1183 / 09059180.00002009$ 